\title{
3-PhaseTransmission Line voltages regulation Using FACTs (Flexible Alternating Current Transmission System)
}

\author{
HaiderAli,MohsinAmin,S.W.AliShah,M.Baseer,UmarFarid \\ CIIT Abbottabad Campus, Engineering Department KPK Pakistan
}

\begin{abstract}
This paper concentrates upon the behavior of SVC (Static VAR Compensator) to improve the efficiency of transmission line. The functional structure for SVC built with a TCR (Thyristor controlled Reactor) \& TSC (Thyristor Switched Capacitor) \& its model are described. The model is based on regulating voltage by controlling the amount of reactive power injected into or absorbed from the power system. The reactive power is injected or absorbed by controlling the firing angle of TSC or TCR respectively. MATLAB is used to carry out simulations of the system under study and results are shown to approach the behavior of SVC to improve the efficiency of transmission line.
\end{abstract}

Keywords: SVC, Thyristor, Transmission line, Simulations, Reactive power

\section{Introduction:}

Numerous techniques are implemented to regulate the output voltage like the use of transformers (OLTC) to change the turn's ratio and guarantee a voltage within a safe range [1].Using OLTC and relay (AVC) to a change the turn's ratio of the transformer coils in order to maintain voltage at fixed level [2].Placing capacitors in distribution feeder is also a technique to regulate the voltage and improve power quality [3]. Using synchronous condensers to regulate voltage and control the power delivered reactive power and generation [4].AVC relay used along with (LDC) line drop compensation for regulation purpose [5]. Employing static synchronous compensator

(STATCOM) for regulation purpose and reactive power control is the efficient technique compared to the conventional techniques [6].PID employed to control static Var compensator (SVC) improves the system performance and easy to implement [7]. Combination of super conduction magnetic storage (SEM) and SVC used for the stability of voltage and power [8].

In Pakistan electricity demand is increasing gradually and fluctuations occur with the changes in load. To reduce these fluctuations and variations in voltage, SVC is installed. For this purpose real time data of four power houses of SATPARA DAM situated at SKARDU namely 1, 2, 3\& 4 is taken. The power house 3 is taken for study. Variations in voltage are observed at power house 3, therefore SVC is installed at the mid of power house 3 and bus bars. Flexible Alternating Current Transmission Systems (FACTS) are new innovative technology based devices that are capable of alternating voltage, phase angle, impedance and/or Susceptance at particular points in power system. Among the FACTS controllers, Static VarCompensator (SVC) is a device that Provides fast acting dynamic reactive compensation for voltage support during contingency events which would otherwise depress the voltage for a significant length of time. SVC also dampens power swings and reduces system losses by optimized reactive power control.

\section{Sve Model:}

SVC is built up with reactors and capacitors. The configurationof,TCR-TSC (ThyristorControlled. Reactor-Thyristor Switched Capacitor) is used in this model.

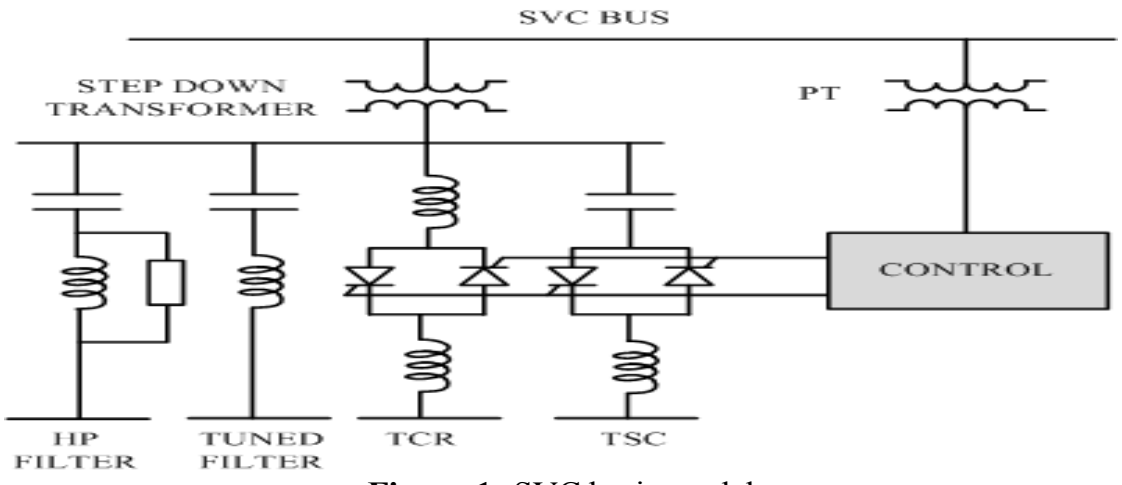

Figure 1: SVC basic model 
SVC is connected with the transmission line through a step down transformer and is represented in figure 1. Step down transformer is used for the ratings of thyristor and absorbed or inject reactive power. Potential transformer (PT) is used for sensing purpose. If the voltage exceeds from the reference value then TCR is activated and when voltage reduces from the reference then TSC is activated. Voltage is controlled through susceptance (Bsvc). The susceptance is determined by the firing angle $(\alpha)$ of the thyristors. Where $\mathrm{B}=2(\mathrm{pi}-\alpha)+\sin 2 \alpha \mathrm{pi} * / \mathrm{xL}\left[\alpha=90^{\circ}\right.$ to $\left.180^{\circ}\right](1)$

Here $\mathrm{pi}=180$.

The most suitable range of the firing angle is in between 90 to 180 Degrees. If the real power consumed by the SVC is assumed to be zero, then:

$\mathrm{Psvc}=0(2)$

Qsve $=-\mathrm{V}^{2} \operatorname{Bsvc}(3)$

Where $\mathrm{v}$ is the bus voltage magnitude, when the reactive power at the bus varies, the susceptance is varied subject to the limits. Reactive power is a function of square of the bus voltage. Hence the reactive power generated decreases as the voltage decreases.

The SVC can both supply as well as absorb reactive power at the bus it is connected to by control of the firing angle of the thyristor elements, By controlling the firing angle $(\alpha)$ of the thyristors the device is able to control the bus voltage magnitude. Changes in $\alpha$ results in changes on the current and hence, the amount of reactive power consumed by the inductor. The basic control strategy is to keep the transmission bus voltage with in certain narrow limits defined by a controller droop and the firing angle $\alpha$ limits $\left(90^{\circ}<\alpha>180^{\circ}\right)$.

\section{Single Line Diagram:}

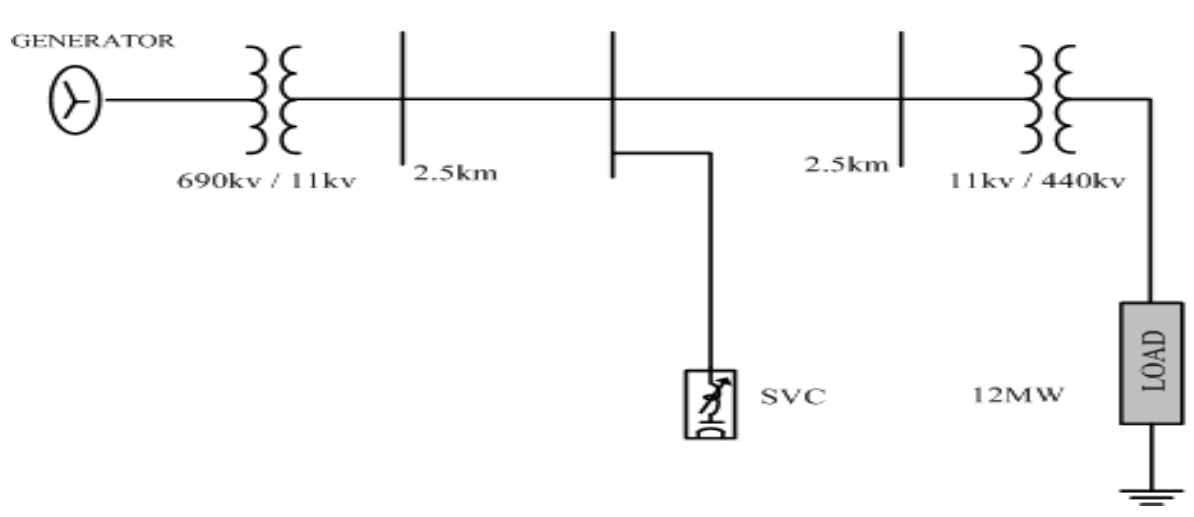

Figure 2: single line diagram

In fig. $2 \mathrm{SVC}$ of rating18 Mvarstabilizes or regulates voltage on 690 volt system. The SVC consist of a $690 \mathrm{v} / 11 \mathrm{kv} 3000 \mathrm{kV}$ coupling transformer, One 6.54 Thyristor controlled reactor bank(TCR) and Three 5.64 Mvar Thyristor switched capacitor banks(TSC1, TSC2, TSC3) connected on the secondary side of transformer.

When TSC's are switched in and out, the switching allows a discrete variation of the secondary reactive power from zero to 16.92 Mvar capacitive by steps of 5.64 Mvar, Where as phase control of the TCR allows a continuous variation from zero to 6.54 Mvar inductive. The leakage reactance of the transformer $9 \%$ is taken into account then the SVC equivalent susceptance seen from the primary side can be varied continuously from $-1.04 \mathrm{pu} / \mathrm{MVA}$ fully inductive to $2.12 \mathrm{pu} / 100 \mathrm{MVA}$ fully capacitive.

The main function of SVC controller is that it monitors the primary voltage and sends appropriate pulses to 24 thyristors 6 thyristors per three phase bank in order to get the susceptance required by the voltage regulator.

Each three phase bank is connected in delta because during normal balanced operation, the zero sequence tripplen harmonics $\left(3^{\text {rd }}, 9^{\text {th }} \ldots \ldots\right)$ must remain trapped inside the delta those results in reducing harmonics injection into the power system. Representation of the power system is $12 \mathrm{MW}$ load. The internal voltage of the equivalent can be made variable by using programmable source in order to observe the SVC dynamic response to change the fluctuations in system voltage.

\section{Results:}

MATLAB is used to carry out simulations of the system under study and results are shown to approach the behavior of SVC to improve the efficiency of transmission line voltages. On power house 3 variations in voltage in occurs with due to speed \& excitation and variation are shown in figure 3. 


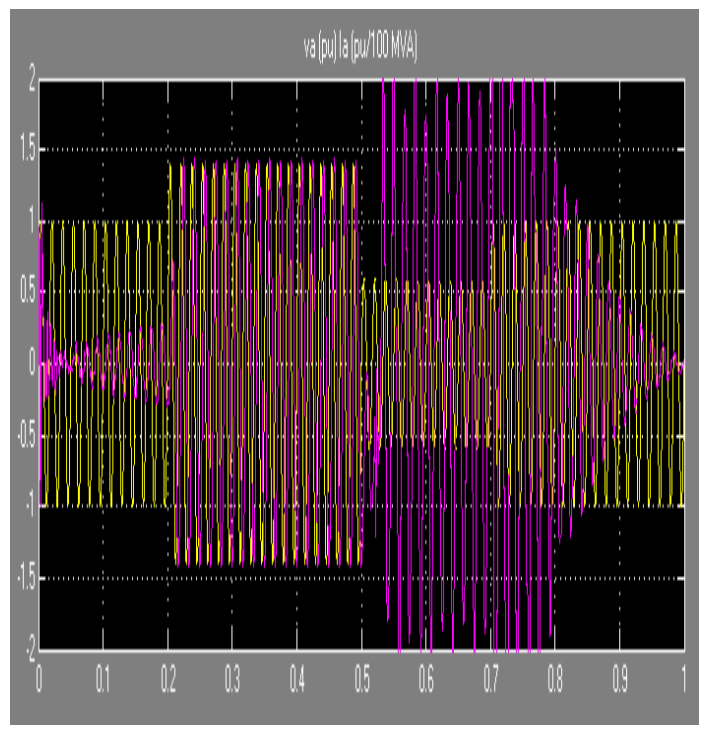

Figure 3: Voltage Variation

In the above fig: 3 the yellow curve show the voltage and the indigo (purple) shows the current. To overcome these voltage variations SVC is installed on the mid-point of the transmission line. It is observed that the voltage is stabilized by installing SVC

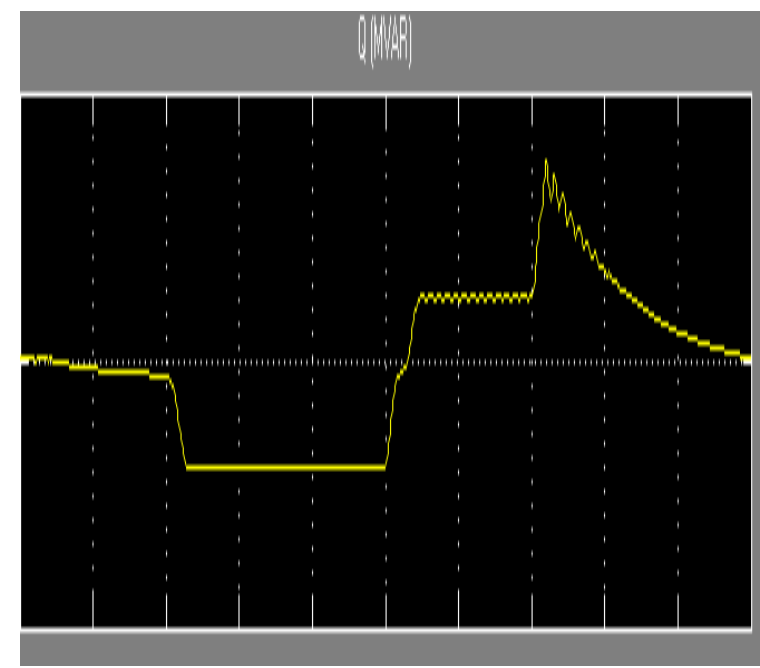

Figure 4: Reactive power inject or absorbed

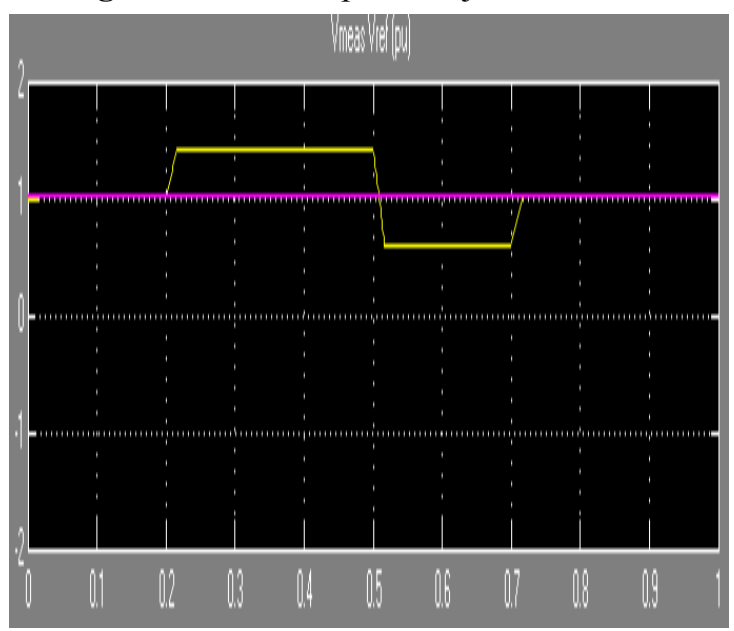

Figure 5: Stability in Voltage 
When the voltage is increased from the reference value that is 1.01 per unit, then the reactive power absorbed is 5.72 Mvar, and when voltage is decreased then the reactive power injected 16.92 Mvar. It is noted here that changes in firing angle result on changes in the current, and hence the amount of reactive power consumed by the inductor. As load increases, the firing angle decreases and hence more amount of reactive power is consumed by the inductor, and vice versa.

\section{Conclusion}

In this paper, thebehavior of SVC is observed and its model is described. The model is based on regulating voltage by controlling the amount of reactive power injected into or absorbed from the power system. Simulations carried out confirmed that SVC( Static Var Compensator) has provided the stability in voltage that is 1.0 per unit, reducing the fluctuations and variations in the voltage at the power house 3 connected to the bus bars.

\section{References}

[1] C. Gao, and M. A. Redfern. "A review of voltage control techniques of network with distributed generations using on-load tab changer transformers, 45th Universities Power Engineering Conference (UPEC),2012

[2] Z. Dong, et al., "Capacitor switching and network reconfiguration for loss reduction in distribution system," in Proc Power Engineering Society General Meeting Conf., pp. 1-6, 2006.

[3] C. T. Su, and C. S. Lee, "Modified differential evolution method for capacitor placement of distribution systems," in Proc. Transmissions and Distribution Conf., pp. 208-213, 2002.

[4] Yuan-Yin Hsu, and Wah-Chun Chan, "Coordinate frequency and voltage control of synchronous generation," IEEE Transaction on aerospace and Electronic System, vol. 23, no. 1, Jan. 1987

[5] H. A. Gil and G. Joos, "Models for quantifying the economic benefits of distributed generation," IEEE Transaction on Power Systems, vol. 23, no. 2, pp. 327-335, May. 2008 .

[6] H. F. Wang. "Interaction and multivariable design of STATCOM AC and DC voltage control." Electrical power energy system, vol. 25, no. 5, pp. 387-394, Jan. 2003

[7] Mark Ndubuka, "Voltage Stability Improvement using Static Var Compensator in Power Systems", Leonardo Journal of Sciences Issue 14, pp. 167-172, January-June 2009

[8] IssarachaiNgamroo "Robust Frequency Stabilisation By Coordinated Superconducting Magnetic Energy Storage with Static Synchronous Series Compensator", International Journal of Emerging Electric Power Systems: Vol. 3: No. 1, August 2005. 